\title{
PLANTAS MEDICINAIS DE MINAS GERAIS, BRASIL
}

\author{
Telma Sueli Mesquita Grandi (1) \\ Jorge Antônio da Trindade (2) \\ Marcio José Filardi Pinto (2) \\ Liliana Lobo Ferreira (3) \\ Agostinho Carlos Catella (3)
}

\begin{abstract}
RESUMO - Esse trabalho foi baseado em entrevistas junto às pessoas e raizeiros que fazem uso de plantas medicinais em Minas Gerais, sudoeste do Brasil, e as comercializam, de 1983 a 1988. Tem a finalidade de preservar o conhecimento popular. Foram registradas a profissão, idade, e condição social dos entrevistados. Foram visitadas 84 cidades mineiras onde, por indicação ou doação, foram coletadas 5000 exsicatas, que foram reunidas em 84 famílias, 246 gêneros e 311 espécies, depois de examinadas e determinadas, dentro das referências mais atualizadas possíveis. Para cada espécie foram anotadas em fichas os nomes vulgares, partes usadas e indicações medicinais, e o número de vezes que foram citadas no total de entrevistas realizadas. $\mathrm{O}$ trabalho é cumulativo, podendo ser constantemente ampliado com a reunião e sistematização de novas informações, servindo como base para escolha das espécies a serem estudadas no campo da fitoquímica, farmacologia e parasitologia.
\end{abstract}

Palavras-chave: Plantas medicinais - uso popular - Minas Gerais.

\begin{abstract}
This study is based on interviews during 1983-1988 of people who use and market medicinal plants in the state of Minas Gerais in south east on Brazil. The aim is to preserve popular local knowledge regarding the use of plants for medicinal purposes. The popular common name, the medical prescription and methods of preparation, the plant part use and the frequency with each plant was cited in the interview samples, are described for each species. The profession, age and social condition are given for each interviewee. A total of 84 cities were visited, resulting in the collection of 5000 dried herbarium specimes which have been classified into 311 species of 246 genera and 84 families, according to the most recent taxonomic nomenclature. This study permits constant revision and updating and serves as a basis for the choice of species with pharmacological, parasitological and therapeutic potential.
\end{abstract}

Key words: Medicinal plants - Popular knowledge - Minas Gerais.

(1) Professor Adjunto do Departamento de Botânica UFMG.

(2) Estudantes de Farmácia da UFMG - monitores do Depto. de Botânica - UFMG.

(3) Biólogos pela UFMG. Bolsistas do CPq-UFMG.

(4) Agência financiadora $\mathrm{CPq} / \mathrm{UFMG}$ 


\section{Introdução}

O uso das plantas medicinais começou com a própria história do homem, como coloca Stuart (1979), através de experiências de ensaio e erro. No Brasil, o uso de plantas medicinais está muito ligado à cultura indígena, como nos relata Martius (1844).

Mas a influência européia é inegável, visto a grande quantidade de plantas introduzidas em nossas hortas e largamente utilizadas não somente como medicamento mas também como ervas aromáticas. Nas cidades históricas de Minas Gerais, às vezes encontramos algumas espécies introduzidas, ocorrendo como subespontâneas nos terrenos baldios e muros de pedras, completamente adaptadas ao nosso clima.

Muitas plantas foram trazidas da África pelos negros e, além de serem usadas como medicinais, fazem parte dos ritos afro-brasileiros e, para grande parte da população, têm poderes mágicos.

O objetivo principal desse trabalho é a preservação do conhecimento popular sobre o emprego das plantas como medicamento, pois, com o advento dos medicamentos industrializados, o interesse por esse conhecimento foi diminuindo e muitos raizeiros desapareceram sem deixar registradas suas experiências, que são fonte importante parte os trabalhos de fitoquímica, farmacologia e parasitologia. Outros objetivos procurados foram, um maior conhecimento sobre os nomes vulgares das plantas em Minas Gerais, seu emprego e parte das plantas empregadas. Para isso, usamos o trabalho de nossos alunos, permitindo uma amostragem maior em Minas Gerais e além disso, servindo como estímulo ao desenvolvimento e curiosidade deles como também dispensando a ajuda financeira de orgãos de pesquisa.

\section{Metodologia}

Os alunos da Universidade Federal de Minas Gerais, das disciplinas Plantas Medicinais e Botânica Aplicada à Farmácia, no período de 1982 a 1986, seguindo a orientação do Professor da disciplina, entrevistaram mais de 500 populares que utilizam plantas como medicamento em todo o Estado de Minas Gerais, percorrendo 84 cidades, sendo a pesquisa mais intensa na região metalúrgica do Estado.

Foram coletadas mais de 5500 exsicatas para identificação no laboratório, porém $10 \%$ das mesmas foram eliminadas por estarem incompletos ou serem de impossível identificação botânica. As espécies muito conhecidas, apesar de imcompletas, foram consideradas. A identificação foi realizada de acordo com a metodologia usual em botânica, usando chaves de identificação para famílias e gêneros. Um exemplar de cada exsicata foi depositado no herbário BHCB, sendo que alguns ainda estão em estudo, e foram colocados no trabalho apenas a nível de gênero.

Foram encontradas, até o momento 84 famílias, 246 gêneros e 311 espécies que podem ser aumentadas à medida que novas entrevistas e observações 
forem sendo registradas, pois o trabalho é cumulativo.

Para que as informações populares recebessem um tratamento uniforme, as indicações medicinais foram incorporadas na linguagem científica, mas se procurou fazer um glossário das mais usadas para facilitar a leitura do trabalho.

Dados sobre o tipo de entrevistados foram acrescentadas ao trabalho por acreditarmos que é importante conhecermos as pessoas que utilizam plantas como medicamento. Além disso, foi verificado o número de vezes que a planta foi citada como medicinal. Dados sobre nomes vulgares, partes usadas, e indicação medicinal foram coletados em todo o estado.

\section{Resultados}

\section{TABELA I}

Lista das Famílias, Especies, Nomes Vulgares, Partes Usadas, Forma de Preparo e Indicações Medicinais, citadas como medicinais em 84 cidades de Minas Gerais.

Agavaceae

Agave americana L. - piteira

$\mathrm{O}$ caule em vinho ou decocto é usado nos reumatismos.

Polyanthes tuberosa L. - angélica

Toda a planta em forma de infuso é usada para o estômago como calmante.

\section{Alistamaceae}

Echinodorus macrophyllus Kunth. - chapéu de couro.

$\mathrm{O}$ decocto das folhas é tido como diurético, colagogo, depurativo, laxativo, anti-reumático, analgésico.

\section{Amaranthaceae}

Althernanthera tenella Colla - piriquito, perpétua.

O decocto ou cozimento é tido como depurativo, diurético, antinflamatório, béquico, colagogo e nas inflamações do útero.

Amaranthus sp. - carurú de porco.

$\mathrm{O}$ decocto das folhas é tido como diurético, antinflamatório, como emoliente e no fortalecimento de dentes e ossos.

Gomphrena globosa L. - perpétua roxa, angélica.

O decocto de toda a planta é usado como diurético, na acidez estomacal, nas doenças das vias respiratórias, e ajuda na digestão.

Iresine herbatii Wk. - coração magoado, mangericão de N. Sr. dos Passos, republicana, catinga de mulata.

O decocto das folhas é usado nas doenças do coração e nos edemas. Toda a planta em infusão, ingerida ou em banhos, é utilizada para asma, artrite, reumatismo, gota e histeria. 
A casca do caule é usada em dococto na diabete e como tônico e as folhas, em decocto, como depurativo, colagogo, na diabete e nos regimes de emagrecimento.

Mangifera indica L. - mangueira.

O caule ou as folhas são usadas, em infuso ou decocto, como calmante nas febres, gripes, como emoliente e no escorbuto.

\section{Annonaceae}

Annona muricata L. - graviola.

O decocto das folhas é usado para controle e tratamento da diabete e nos regimes de emagracimento.

Xylopia aromatica Mart. - pimenta de macaco.

As folhas, a casca do caule ou o fruto, em infuso e decocto, são tidos como antinflamatório e digestivo.

Apocynaceae

Allamanda cathartica L. - alamanda, erva mate, quatro patacas amarelas, dedal de Aurélia.

As folhas, sob a forma de decocto, são usadas nos casos de cistites, uretrites, e nas afecções renais, podendo ser eméticas. Externamente usadas contra sarnas.

Allamanda violacea L. - quatro patacas.

As folhas, sob a forma de decocto, são usadas como eméticas.

Catharantus roseus (L.) G. Don. - boa noite, vinca.

As folhas, em forma de decocto, são usadas na diabete e hipoglicemia.

Hancornia speciosa Gomes - mangaba.

A casca do caule é usada, em decocto, para a diabete e nos regimes de emagrecimento.

Macrosyphonia velame (St. Hil.) Muell Arg. - velame, velame branco, velamo, velame do campo.

Toda a planta, em forma de decocto, é tida como depurativa, anti-reumática, anti-sifilítica e nas úlceras pépticas. $\mathrm{O}$ decocto das folhas é usado para gripe, febres e hemorragias. A raiz, em forma de decocto ou vinho, é usada como depurativo do sangue, na blenorragia, moléstias da pele, feridas, úlceras, tumores, reumatismos e inflamação dos rins.

Nerium oleander L. - espirradeira.

Toda a planta, como infuso e decocto, é usada nas doenças do intestino e coração. Mas essa planta é altamente tóxica podendo causar a morte.

Thevetia nerifolia Juss. - chapéu de napoleão.

As sementes ou o fruto, fervidos em água, são usados no enfarte.

Planta altamente tóxica.

Aquifoliaceae

Ilex diurética Mart. - congonha, Congonha Senhora da serra.

A folha, sob a forma de decocto ou infuso, é usada como diurética, na hipertensão arterial e nas infecções urinárias (rins e bexiga). O caule macerado, é 
usado como cicatrizante.

\section{Araceae}

Monstera sp. - imbé, chagas de S. Sebastião.

$\mathrm{O}$ decocto das folhas é usado externamente em compressas na amigdalite e sinusites.

Xanthosoma violaceum Schott. - taioba.

O tubérculo, sob forma de pó, é usado na hemorróida e a folha, em infuso, é usada nas doenças de pele.

Aristolochiaceae

Aristolochia sp. - jarrinha, papo de peru, milhome, cipó milhome, cassaú.

As raízes ou a casca do caule, sob a forma de infuso ou alcoolatura, são usadas para reumatismo, amenorréia, excitante, abortivo. As folhas, em decocção, são usadas em hipertensão arterial.

Aristolochia cymbifera Mart. et. Zucc. - jarrinha, papo de perú, milhome.

Toda a planta, sob a forma do infuso, é usada no reumatismo.

Asclepiadaceae

Asclepias curassavica L. - oficial de sala, paina de sapo, erva de rato.

A raiz, em infusão ou decocção, atua, em doses muito pequenas, como laxativo. Em maior proporção é venenosa e serve para matar bernes.

\section{Balsaminaceae}

Impatiens balsamina L. - beijinho, beijo branco.

As flores, em infusão ou decocção, misturadas ou não com a rosa branca, são usadas nas doenças do aparelho genital feminino.

\section{Bignoniaceae}

Anaemopegma mirandum (Cham.) P.DC - catuaba, verga-tensa, arnica.

Principalmente raízes, casca do caule ou folhas são usadas sob a forma de infuso, vinho ou xarope para impotência sexual, doenças venéreas masculinas e como excitante, esgotamento nervoso.

Jacaranda sp.- carobinha.

Raízes ou folhas, em infuso, decocto, vinho ou na cachaça, são usadas puras ou em associação com outras plantas como anti-sifilítico, anti-reumático, nas doenças da pele, vulneráveis e nas inflamações. O caule, em infuso é usado para coceiras.

Jacaranda sp2 - caroba.

Raízes ou folhas em infuso, decocto, vinho ou na cachaça.

Pyrostegia venusta Mart. - cipó de São João.

As flores ou os ramos săo usados, sob a forma de infuso ou decocto, para reumatismos, bronquites, doenças dos rins e dor em volta do umbigo. Houve citação também para o vitiligo e toxoplasmose.

Tabebuia ochracea (Cham.) Standl. - cinco folhas, ipê. 
As folhas são usadas em decocto como anti-sifilítico, nas blenorragias e doenças dos rins.

Tunanthus elegans Miers. - cipó cravo.

Raízes, caules ou folhas sob a forma de decocto, infuso e vinho são usadas na impotência sexual, reumatismo e fraqueza.

\section{Bixaceae}

Bixa orellana L. - urucum.

As folhas, sob a forma de decocto, são usadas nas gripes e tosses. As sementes, em decocto, para bronquites, no sarampo incubado e como febrífugo. Prolonga a vida na doença de Chagas. Antídoto contra o veneno de mandioca.

\section{Boraginaceae}

Borago officinalis L. - boragem.

As folhas, sob a forma de infuso, decocto, cataplasma, salada ou po, são antinflamatórias nas cistites e nefrites. Usada nos sarampos e como galactagogo.

Cordia verbenaceae DC. - maria preta, crista de galo, erva baleeira.

As folhas são usadas, em infusos, contra as cefalgias.

Heliotropium indicum L. - boragem brava, crista de galo.

As folhas, sob a forma de infuso, decocto e tintura, são usadas no reumatismo, gota, tosses, coqueluche, anti-hemorroidal, resolutivo nos abcessos, furúnculos, estomatites, moléstias cutâneas e como adstringentes.

Symphytum uplanticum Nyman. - confrei, consólida maior.

As raízes ou folhas, sob a forma de infuso, decocto, pomada de pó, são usadas em frieiras, câncer, doenças do fígado e estômago, inflamações, azias, doenças da pele, queda de cabelo, malária e esquissostomose, antianêmico, com emolientes, nas fraturas ósseas e dores lombares, esquecimento, hepatites, úlceras, erisipela e hipertensão arterial.

Tournefortia paniculata Cham. - marmelinho do campo.

As folhas e o caule, sob a forma de infuso ou decocto, são usados como diuréticos, para problemas renais como infecções e cálculos, e para infecções da bexiga.

\section{Buddlejaceae}

Buddleja brasiliensis Jack. - barbasco, chinelo de velho.

Folhas ou raízes, sob forma de infuso ou decocto, são usadas nas gripes, bronquites e pneumonias como emoliente. $\mathrm{O}$ decocto é usado em banhos contra inflamações dérmicas, artrites e inchações.

\section{Cactaceae}

Pereskia aculeata Miller - "ora pro nobis".

As folhas, cozidas ou em saladas, são usadas na alimentação de pessoas desnutridas e anêmicas. 
Cleome spinosa Jack. - mussambé de espinho.

Toda a planta, sob a forma de decocto, é usada na asma, bronquite, cefalgias e leucorréia.

\section{Caprifoliaceae}

Sambucus australis Cham. et Schlech. - Sabugueiro.

As folhas ou flores secas, em infuso, decocto e tinturas, são usadas nas gripes, intoxicações do fígado e anginas pectoris.

\section{Caricaceae}

Carica papaya L. - mamoeiro.

As sementes, ingeridas cruas, são consideradas vermífugas. As flores femininas, sob a forma de infuso e decocto, são usadas como peitorais, nas doenças do fígado e cefaléias. $O$ fruto é estomáquico e digestivo.

\section{Caryophyllaceae}

Dianthus caryophyllus L. - cravo.

Toda a planta, em decocto, é usada como colírio das doenças dos olhos.

Dianthus sinensis L.

Toda a planta, em decocto, é usada como colírio nas doenças dos olhos.

\section{Celastraceae}

Maytenus sp. - espinheira santa do Mato Grosso.

As folhas, sob a forma de decocto, são usadas como aperitivas, nas úlceras, nas doenças dos rins, fígado, estomacais e como antinflamatórias.

Maytenus ilicifolia M. - espinheira santa, folha santa, divina, espirradeira.

$\mathrm{O}$ decocto das folhas é usado como antinflamatório nas úlceras estomacais, azia e dores de estômago, como analgésico, cicatrizante, e vulnerária.

Observação: diminui a secreção láctea nas mulheres lactentes.

Maytenus salicifolia Reiss. - cafezinho do mato.

Toda a planta, sob a forma de decocto, é usada para pruridos e alergias em banhos.

\section{Chenopodiaceae}

Chenopodium ambrosioides L. - erva de Sta. Maria.

As sementes ou folhas são usadas como anti-helmíntico, aromático, emenagogo, vulnerário e nos reumatismos. Sendo abortiva, não é recomendada para mulheres grávidas. É mais usado sob a forma de sumo, infuso e decocto.

Spinacea aleraceae L. - espinafre.

As folhas, cozidas, são usadas na anemia e como antiemética.

\section{Commelinaceae}

Tradescantia diuretica Mart. - trapoeiraba, capoeraba.

A planta inteira, sob a forma de infuso ou emplasto, é usada para hidropsia, reumatismo e ascite. 
Zebrina pendula Schnizlein. - trapoeiraba listada.

Toda a planta, sob a forma de infuso, decocto ou emplasto, é usada como cicatrizante, emoliente, diurético, nas bronquites, reumatismo, hidropsia e vitiligo.

\section{Compositae}

Acanthospermum australe (Loef.) Kuntze - carrapicho benzinho, fel de terra.

O decocto, de toda a planta, é usado como vermífugo, febrífugo, na desinteria e na icterícia.

Achillea millefolium L. - macelão, mil em rama, mil folhas, mil homens, sabugueirinho.

Todo o vegetal ou folhas, sob forma de infuso é usado como anti-espasmódico. Achirocline satureoides Dc. - macela, marcela.

As folhas ou flores são usadas como antiemética, estomacal e doenças do couro cabeludo.

Ageratum conyzoides L. - erva de S. João, mentrasto, mentruste.

Toda a planta, sob a forma de infuso e decocto, é usada como antiespasmódico, estomáquica, ocitóxica, emenagoga e abortiva.

Anthemis cotula L. - macelinha, marcelinha, macelinha galega.

Toda a planta, em infuso, macerado e vinho, é usada como calmante, estomáquico, anti-diarréico, febrífugo, carminativo, anti-epiléptico e gastrinterite.

Anthemis tinctoria L. - camomila amarela.

As flores ou toda a planta, sob a forma de infuso ou decocto, são usadas para gripes, febres, como calmante e nos resfriados.

Arctium lappa L. - bardana.

As raízes, em infuso e decocto, são usadas em cólicas de rins, gota, furunculose, queda de cabelo, reumatismo, depurativo, diurético, cálculos renais e antídoto contra envenenamento por mercúrio.

Artemisia absinthium L. - losna.

As folhas, em infuso, decocto e macerado, são usadas para problemas de estômago, e fígado, vermífugas contra as solitárias, na esquistossomose e antieméticas.

Artemisia aff. vulgaris L. - artemísia, absinto, sálvia.

$\mathrm{O}$ infuso, das sumidades floridas, é usado como antiespasmódico, doença de São Guido, como vermífugo, anti-malárico, blenorragia, carminativo e nas convulsões infantis.

Baccharis dracunculifolia DC. - alecrim do campo, vassourinha.

$\mathrm{O}$ decocto das folhas é usado como febrífugo.

Baccharis trimera DC. - carqueija amarga, carqueja.

Toda a planta, em decocto, é usada como tônico, febrífugo, eupéptico, colagogo, na diabete, em regimes de emagrecimento, para o fígado, cálculos biliares, diurético e doenças do couro cabeludo.

Bidens pilosa L. - picão, carrapicho, picanço.

Toda a planta, sob a forma de infuso ou decocto, é usada na hepatite e problemas do fígado.

Chaemamelum nobile (L.) All. - camomila romana. 
Plantas medicinais de Minas Gerais...

As flores, sob a forma de decocto, são usadas como antiespasmódica.

Chaptalia nutans Polak. - língua de vaca.

As folhas, sob a forma de infuso ou decocto, são usadas como resolutivo, desobstruinte, balsâmico, anticatarral, nas gripes, insônia, cefalalgias, e erupções cutâneas.

Chrysanthemun parthenium (L.) Bernh. - artemigem dos jardins.

A sumidade florida, sob a forma de decocto, é antiespasmódica, emenagoga, e abortiva.

Cynara solymus L. - alcachofra.

Folhas e ramos, em infusão, são usados em problemas estomacais e como colagogo.

Elephantopus scaber L. - fumo bravo.

Toda a planta, na forma de decocto, é usada nas tosses e bronquites.

Emilia sonchifolia (L.) DC. ex Wight. - Emília, pincel de estudante, pincel.

Todo o vegetal, ao natural, ou em infuso e decocto, é usado como febrífugo, antiasmático e nos problemas oculares.

Galinsofa parvifolia Cav. - fazendeiro, picão branco.

$\mathrm{O}$ infuso ou decocto, da planta inteira, é usado como vulnerário, excitante, antiescorbútico e aromático.

Helianthus anuus L. - girassol.

O decocto da semente é usado na sinusite. O óleo da semente e as folhas são usadas nas contusões e como cicatrizante.

Lactuca sativa L. - alface.

Talo, raízes ou folhas, em decocto ou salada, são usadas como calmante e nas cefaléias infantis.

Lychnophora spl. - arnica.

$\mathrm{Na}$ alcoolatura e na cachaça, os ramos servem para passar em machucados e picadas de insetos.

Lychnophora sp2 - arnica.

Os ramos, em alcoolatura, são usados, em fricções, nas contusões.

Lychnophora brunioides Mart. - arnica.

$\mathrm{O}$ caule e as folhas, sob a forma de alcoolatura e infuso, são usados como antinflamatório, descongestionante, nos reumatismos e nas contusões, picadas de insetos e cefaléias. Internamente é usada nas febres, catarros e nos problemas renais.

Mikania sp. - orelha de cachorro.

$\mathrm{O}$ decocto, das folhas ou raízes, é usado nas frieiras, inflamações, vulnerário. $\mathrm{O}$ sumo da folha é usado para luxações.

Mikania glomerata Spreng. - guaco.

As folhas, em infuso, decocto ou xarope, são usadas como expectorante, béquico, nas bronquites, asmas e gripes.

Mikania sp. - micânia, coração de Jesus.

A planta florida, sob a forma de infuso e decocto, é diurético e usada como poderoso albuminúrico.

Mikania hirsutissima DC. - cipó cabeludo, cipó miluca. 
Toda a planta, quando florida, é usada principalmente, em decocto, nos problemas renais, hipertensão, nas dores lombares e como calmante.

Pluchea quitoc DC. - quitoco, tabacarana, marcelão.

Toda a planta, sob a forma de infuso, ou queimado na cachaça, é usado como emenagogo e nas flatulências, bronquites e reumatismos.

Solidago microglossa DC. -Ponta livre, arnica do campo, arnica do mato, escovinha, erva lanceta.

O infuso de toda a planta é usado nas anginas pectoris, nas contusões, como litagogo e em banhos para o reumatismo.

Sonchus oleraceus L. - serralha, dente de leão.

As folhas, em salada ou em seu sumo, são usadas em doenças da pele como manchas, impingens, erupções e como depurativo, estomacal e nas diarréias.

Tagetes erecta L. - cravo de defunto.

$\mathrm{O}$ infuso de toda a planta é usada na angina pectoris e contra corrimento vaginal.

Tagetes minuta L. - cravinho, enxota.

Toda a planta, sob a forma de emplasto, é usada nas contusões.

Tanacetum vulgare L. - catinga de mulata, tasneira, pluma da Pérsia, catinga de porco.

Toda a planta, sob a forma de infuso e decocto, é usada como estomacal, depurativo, colagoga e como vermífuga.

Taraxacum officinale Wigg. - dente de leão, serralha.

Raízes ou rizomas em alcoolatura ou decocção e as folhas em salada são usadas como amargo, colagogo, diurético, depurativo, anemia, icterícia, fraqueza, diabete, dor na coluna.

Trixis divaricata (H.B.K.) Spreng. - solidônia.

As folhas e ramos novos, sob forma de decocto ou colírio, são usados na conjuntivite, lavagem ocular e metrorragia.

Vernonia condensata Baker - boldo, alumã, chantinon, necroton, alonça, marcelão, boldo do chile.

As folhas sob forma de infuso são usadas como colagogo, estomacal e problemas intestinais.

Vernonia polyanthes Less. - assa peixe.

Toda a planta em infuso, decocto ou melito é usada nas bronquites, pneumonias, gripes, febres e resfriados, béquico. Nas torções, contusões e luxações usa-se o emplasto ou o sumo das folhas.

\section{Convolvulaceae}

Cuscuta racemosa Mart. - cipó chumbo.

Toda a planta, sob a forma de infuso ou decocto ou emplasto, é usada como tônica, anticatarral, adstringente, diurética e anti-hemorroidal.

Operculina turpethum (L.) A. Silva Manso - jalapa.

As raízes, sob a forma de infuso, decocto, ou xarope, são usadas como purgativas, depurativas e nas úlceras. 


\section{Crassulaceae}

Cotyledon orbiculata L. - bálsamo.

Folhas e talos em salada ou o sumo são usados para úlceras, dor de estômago, gastrite, como vulnerário, nas gangrenas, dores de ouvido e para curar epilepsias.

Bryophyllum pinnatum L. - Folha de fortuna.

As folhas são usadas aquecidas para curar cefalalgias e dismenorréia.

\section{Cruciferae}

Brassica nigra (L.) Koch - mostarda negra.

Sementes são usadas socadas como hemostático e as folhas em salada como digestivas. As pessoas acreditam que a semente pode curar a dor em locais diferentes daquele em que é colocada e onde causa uma queimadura. A esse processo dão o nome de sinapismo.

Brassica oleracea L. - couve.

O sumo das folhas é usado para problemas de estômago, anemia, e para tirar a dor de machucados.

\section{Cucurbitaceae}

Apodanthera smilacifolia Cogn. - cipó azougue, cabaça amargosa.

$\mathrm{O}$ decocto das raízes ou frutos é usado como depurativo, nas dores reumáticas e como anti-sifilítico.

Fevillea trilobata L. - fava de Sto. Inácio, gindiroba.

O decocto das favas é usado nas cólicas intestinais.

Luffa operculata Roem. - bucha paulista.

A inalação do decocto da quarta parte de uma bucha seca com uma semente é usada na sinusite.

Momordica charantia L. - melão de S. Caetano.

Toda a planta em infuso ou decocto ou macerada é utilizada contra febres, gripes, bronquites, pneumonias, cólicas, reumatismos, vermífugo no caso da ascaridíase. O sumo das folhas é bom para sarna.

Sechium edule (Jacq.) SW. - chuchu.

$\mathrm{O}$ infuso dos ramos novos é usado na hipertensão e como calmante, além de carminativo.

\section{Cupressaceae}

Cupressus sempervirens L. - cipreste.

A gálbula, sob a forma de decocto, é usada nas varizes, hemorróidas, moléstias do sistema nervoso, metrorragias, desinteria e hérnia.

\section{Dilleniaceae}

Davilla rugosa Poir. - cipó carijó, cipó caboclo, cuitezinho, sambaibinha, cambaíba.

As raízes, em infuso, são usadas em banhos como sedativo e nas angústias. As folhas em decocto são usadas nas úlceras e inchações do aparelho genital mas- 
culino.

\section{Dioscoriaceae}

Dioscorea bulbifera L. - cará do ar.

Os bulbos aéreos, em decocção, são usados como depurativo.

Equisetaceae

Equisetum giganteum L. - cavalinha, rabo de cavalo, caninha de macaco, caninha do brejo.

O infuso ou decocto das ramificações caulinares são usadas para estancar hemorragias principalmente de hemofílicos, nas hemorróidas, doenças da próstata, bexiga e rins e o banho tira a dor no corpo de mulher grávida.

\section{Euphorbiaceae}

Croton antisyphiliticus Muell. Arg. - pé de perdiz, canela de perdiz, rabujo de cachorro, curraleira.

Toda a planta em decocto, ou a raiz em vinho branco, é usada como antinflamatório, depurativo, anti-sifilítico, feridas, eczemas, reumatismo.

Croton salutaris Casar. - Sangue de drago, sangra d'água, mangle.

Folhas, casca e, decocção são usadas para úlceras e estômago e o látex como vulnerário (quebrar um ramo, e passar a água que escorre, sobre a ferida).

Euphorbia pilulifera L. - erva andorinha, erva de Sta. Luzia.

Preparar um xarope do decocto e tomar várias colheres por dia para falta de ar e moléstias das vias respiratórias.

Euphorbia serpens H.B.K. - quebra pedra rasteiro.

Toda a planta, sob a forma de decocto ou infuso, é usada como diurético e litagogo.

Euphorbia tirucalli L. - homem nú, avelós.

O látex diluído em água, II a X gotas por copo, é usado no combate ao câncer.

Joannesia princeps Vell. - cotieira, andá-assú, fruta de cotia, bolheira, boleira.

O óleo da semente ou a decocção das sementes são usados como purgativo e em pequenas doses como antiasmático e depurativo.

Phyllanthus corcovadensis Muell. Arg. - quebra pedra falso.

Toda planta ou as raízes são usadas em infuso ou decocto para as doenças renais como as cistides, litíase, diurético, na hipertensão, e na icterícia.

Phyllanthus niruri L. - quebra pedra verdadeiro.

Toda a planta ou as raízes são usadas em infuso ou decocto para as doenças renais como cistite, litíase, diurético, na hipertensão arterial e na icterícia.

Ricinus communis L. - mamoneira, carrapateira.

O óleo a semente é purgativo; mas não esquecer que a semente não pode ser ingerida, pois é muito tóxica, podendo causar a morte.

\section{Flacourtiaceae}

Casearia sylvestris Sw. - era de bugre, lingua de tiú, bugre.

$\mathrm{O}$ decocto da raiz é depurativo e controla a circulação. 


\section{Gramineae}

Avena sativa L. - aveia.

O fruto sob a forma de decocto, tisana, e cataplasma é emoliente, diurético, laxativo. É usado também na hidropsia e como refrescante.

Coix lacryma-jobi L. - lágrima de N. Senhora, conta de lágrima.

Toda a planta em infuso ou decocto é utilizada como diurética, nas doenças renais e nas cólicas menstruais e na asma.

Cymbopogon citratus (DC. ex Nees) Stapf. - erva cidreira, capim limão, lana, capim da lapa.

As folhas ou rizomas em infuso ou decocto são usadas como calmante ou antiespasmódico nas cólicas, carminativo, expectorante e nas diarréias.

Cymbopogon martinii (Roxb.) J.F. Watson - capim de S. José, capim de S. João.

Toda a planta em infuso é usada para sinusites, gripes, enxaquecas e insônia, tosses rebeldes e bronquite.

Eleusine indica (L.) Gaetner - capim pé de galinha.

Toda a planta, sob a forma de infuso e decocto, é usada na bronquite, diurética, e em mistura ao assa-peixe, cura pneumonia.

Imperata brasiliensis Trin. - sapé, sapé de cobrir rancho.

Toda a planta em decocção é usada nas doenças do fígado e rins e para pedra na vesícula foi citado também para diarréia.

Melinis minutiflora P. Beauv. - capim gordura.

O sumo passado diretamente no couro cabeludo faz crescer e nascer cabelos.

Orysa sativa L. - arroz.

O decocto do fruto coado é usado nas diarréias.

Saccharum officinale L. - cana de açúcar, cana caiana.

$\mathrm{O}$ decocto da parte central de três folhas, adoçado com açucar controla a pressão.

Zea mays L. - milho, milho vermelho.

O decocto dos estigmas do milho são usados como diurético e nas cólicas renais, nas cistites e nefrites.

\section{Labiatae}

Coleus barbatus (Andrews) Benth, - boldo.

As folhas maceradas em água, e à temperatura ambiente, são usadas como colagogo nas dores de cabeça e mal estar, após injestão de bebidas alcoólicas e nos problemas estomacais e digestivos, é usada também na hipotensão arterial.

Glechoma heredacea L. - erva terrestre, hera terrestre.

Toda a planta é usada em decocto como tônica, asma, para afecções respiratórias como bronquites, expectorante, emoliente no controle da hipertensão.

Hyptis carpinifolia Benth. - rosmaninho.

As folhas sob a forma de decocto ou emplasto, são usadas para doenças renais, nas gripes, resfriados e no reumatismo.

Ibosa sp. - incenso.

O decocto da planta toda é utilizado na dispnéia. 
Lavandula angustifolia Miller. - alfazema verdadeira.

Toda a planta, sob a forma de infuso, alcoolatura, cataplasma ou óleo, é usada em casos de reumatismo, anúria, aperitivo, câimbra, sinusite e afecções do fígado e do baço.

Leonotis nepaetefolia $\mathrm{R}$. Br. - cordão de frade, cordão de S. Francisco.

A raiz, em decocção ou em vinho branco, é depurativo do sangue, até $10 \mathrm{~g}$ por litro, acima dessa dosagem é utilizada para impotência. A inflorescência, cozida com a erva cidreira da horta, é usada para tensão pré-menstrual. A planta florida, em decocto, é tida como tônica balsâmica, e antiespasmódica. As folhas, em maceração, são febrífugas, e antidisentéricas.

Leonurus sibiricus L. - macaé, hissopo, marianeira, mané turé, mata pasto, bico de urubú, pasto de abelha, mariquinha, mané magro, santo cílio, manjuliana, porrete, amor deixado.

Todo o vegetal, é considerado em decocto, como antigripal, estomacal, digestivo, curando ainda febrite, hemorróidas e traumatismos.

Melissa officinalis L. - erva cidreira verdadeira.

O decocto, das folhas, é usado como calmante, halitose, antiespasmódico, indicado nas disenterias sanguinolentas, nas febres e resfriados.

As folhas frescas, sobre os olhos, aliviam a inflamação dos mesmos.

Mentha pulegium L. - poejo.

Toda a planta, em decocto ou xarope, é usada nas gripes, resfriados, tosses, bronquites, como expectorante e béquica.

Mentha sylvestris L. - levante.

As folhas ou a sumidade florida e, infuso ou decocto, são usadas nas gripes e resfriados, como expectorante e vermífugas, na hepatite e na afonia, tendo sido citada também para angina.

Ocimum sp. - mangericão roxo.

Toda a planta, em infuso ou decocto, é utilizada para palpitações, circulação, e dispnéia, e angina pectoris.

Ocimum basilicum L. - basilicão, mangericão grande.

$\mathrm{O}$ infuso das folhas é usado para resfriados, estimulante, doenças de chagas, e dores do corpo.

Ocimum gratissimum L. - alfavaca, chá da índia, cravo da terra, favaca, cravo, alfavaca vaqueiro, canelinha de casa.

Sumidades floridas, folhas ou flores são usadas sob forma de infuso, decocto, xarope, maceração, e emplasto, em gripes, resfriados, afonias, sendo indicada também como emoliente, febrífugo, expectorante, béquico, e sudorífero.

Ocimum micrantum Willd. - mangericão branco.

As sumidades floridas, em infuso e decocto, são usadas como estomacais, carminativas e aromáticas.

Ocimum canum Sims. - alfavaca de jardim, chá da Índia, elixir paregórico, canelinha.

Toda a planta, sob a forma de infuso, decocto ou tisana é usada como diurético, estimulante, dispnéia, problemas cardíacos, gripe, insônia, angina pectoris e tônico. 
Ocimum suave Willd. - alfavaca de jardim, atroveram.

As folhas são usadas como sudorífero, expectorante, béquico, nos resfriados e coqueluches, e ainda como estomáquico, nas aftas e gengivites.

Origanum majorana L. - mangerona, orégano.

Toda a planta é usada, sob a forma de infuso, decocto, tintura, pó, xarope ou pomada, como tônico, digestivo, aromático, nas gripes de criança, expectorante, bronquite, asma, problemas de pele, estimulante de secreções estomacais, vulnerária, distúrbios estomacais, contra venenos, dores reumáticas, carminativa, antiespasmódica.

Peltodon radicans Pohl. - paracari, hortelã do campo.

Toda a planta, sob a forma de decocto, é usada para inflamações do fígado e dos rins e a sumidade florida, sob a forma de extrato-fluído, é usada para doenças da pele, como dartros, tinhas e eczemas.

Rosmarinus officinalis L. - Alecrim, alecrim da horta.

Toda a planta, sob a forma de infuso, decocto, pó, tintura, extrato-fluído ou sumo é usada como calmante, cardiotônico, estimulante, emenagogo, peitoral, para gripe, estômago, angina pectoris, curar umbigo, dispnéia, hipertensão arterial, doenças da pele, resfriado, contusões, cefalalgias, dores nos rins, febre do tifo, angústia, depressão, dismenorréia, queda de cabelo, carminativo, exaustão física e intelectual, e como cicatrizante. É abortivo.

Stachys arvense L. - hortelã pimenta.

As folhas, sob a forma de decocto, melito, infuso, ou cozidas, são usadas como vermífugo, expectorante, calmante, peitoral, para infecções, gripe, dor de estômago, carminativo, cólica menstrual, problemas de coração, dor e tosse.

Stachys officinalis L. - sálvia peluda, sálvia falsa, poaia.

As folhas, sob a forma de infuso, decocto, loção, vinho, pó ou xarope, são usadas como calmante, expectorante, anti-gripal, antinflamatório, para hipertensão arterial, resfriados, coração, tosse, vômito e desinteria, problemas hepáticos, picadas de insetos, bronquites, afecções gástricas e afonia.

\section{Lauraceae}

Cinnamomum camphora (L.) J.S. Presl. - canforeiro.

O decocto de toda planta é usado como vulnerário.

Cinnamomum verum J.S. Presl. - canela, canela do ceilão.

As cascas do caule ou as folhas, sob a forma de decocto, são usadas para má digestão, gripe, resfriado, é estimulante, e controla a pressão baixa e os nervos. Acredita-se que o caule misturado a outras plantas, sob a forma de decocto, aumente a probabilidade de gravidez, em mulheres estéreis.

Crypptocarya moscata Mez. - noz moscada.

O pó e o vinho, das sementes, são usados nas doenças cardiovasculares, angina pectoris, como carminativo, excitante e afecções do estômago.

Ocotea pretiosa (Nees) Mez. - sassafraz.

As cascas do caule e as raízes, sob a forma de decocto ou na cachaça, são usados como depurativo, excitante, sudorífero, diurético, emanagogo, contra sífilis e reumatismo. 
Persea americana Miller. - abacateiro.

As folhas, sementes, frutos, cascas ou brotos, sob a forma de decocto, infuso, extrato-fluido, xarope, tintura ou pó, são usadas como digestivo, diurético, colagogo, carminativo, emenagogo, vermífugo, peitoral, para os rins, fígado, urticárias, cálculo renal, queda de cabelo, fortificar os dentes, infecções das gengivas, diarréia, combate a cárie, cefalalgias e contra a hipertensão arterial. $\mathrm{O}$ óleo do fruto tem vitamina A, B, D, E.

\section{Lecythidaceae}

Lecythis pisonis Gamb. - sapucaia.

A cápsula do caule, sob a forma de pó ou seu óleo, são usados como anti-sifilítica e diurético.

\section{Leguminosae-Caes.}

Bauhinia sprendens H.B.K. - escada de macaco.

O decocto da casca do caule é usado como depurativo, excitante, na impotência sexual e contra hemorragia.

Bauhinia sp. - unha de vaca, pata de vaca.

A raiz, folha ou flores sob a forma de infuso, decocção, tintura, ou extrato-fluido, são usadas na diabete, constipação, infecções das vias urinárias, regimes de emagrecimento, como diurético, depurativo e para pernas entrevadas.

Hymenaea stigonocarpa Mart. - jatobá.

A casca do caule, fruto, seiva, ou resina, sob a forma de decocto, xarope, infuso, seiva, emplasto, unguento, melito ou no vinho, são usados como aperitivo, vermífugo, expectorante, estomáquico, adstringente, peitoral, tônico para o cérebro, na asma, úlcera, diarréia, gripe, tosse, anemia e como antinflamatório.

Caesalpinea ferrea Mart. - pau ferro, jucá, fava santa.

O fruto macerado, seguido de decocção, é utilizado nas cefaléias, e como analgésico.

Copaifera langsdorfii Desf. - óleo de copaíba, copaíba.

O óleo da madeira é cicatrizante, vulnerário, laxante, cistites e nefrites.

Senna alexandrina Miller. - sene verdadeiro.

As folhas ou as favas, em infuso ou decocto, são usadas como laxantes.

Senna cathartica (L.) H. Irvin e Barneby - sene falsa, seno, sena.

As folhas e flores, sob a forma de decocto e infuso, são usadas nas gripes, como laxativo, purgativo, depurativo, no sarampo, doenças venéreas e cefaléias.

Senna occidentalis (L.) H. Irvin e Barneby - fedegoso.

Folhas ou raízes, sob a forma de infuso, decocto, vinho ou na cachaça, são usadas nas gripes, rouquidão, como vermífugas, febrífugas, e nas moléstias do fígado.

Schyzolobium parahybum (Vell.) Brake - birosca, chinelo de velho.

Acredita-se que, as sementes, presas ao pescoço de crianças facilitam o nascimento da dentição. 
Amburana cearensis (Fr. All.) A.C.Smith - amburana, imburana.

A semente, em maceração seguida de decocção, é usada na bronquite, asma, rouquidão e como fortificante.

Arachis hipogaea L. - amendoim.

O óleo da semente é nutritivo e afrodisíaco.

Clitoria guyanensis (Aubl.) Benth. - catuaba falsa, arnica do mato.

A raiz, sob a forma de infuso ou decocto, é usada como estimulante dos nervos e músculos.

Desmodium adscendens (Sw.) DC. - carrapicho, carrapicho de beiço de boi, carrapicho de carneiro.

A raiz, sob a forma de infuso ou decocto, é usada na diarréia, problemas renais e intestinais.

Erytrina mulungu Mart. - mulungu.

A casca do caule, em decocto, é usada na asma de origem nervosa.

Indigofera suffruticosa Mill. - anileira, anir, anil.

As folhas ou raízes, sob a forma de infuso e decocto, são usadas como anti-sifilítico, antiblenorrágico, antiespasmódica e antiepilética.

Medicago sativa L. - alfafa.

$\mathrm{O}$ decocto das folhas é usado no reumatismo e na artrite, assim como as folhas ao natural.

Pterodon abruptus Mart. - sucupira, sicupira.

As sementes, na cachaça, ou no Biotônico Fontoura, são usadas como antinflamatório principalmente nas dores de garganta, bronquites, asma e reumatismos.

Spartium junceum L. - giesta.

As flores e ramos são usados, em infuso e decocto, em doenças cardíacas mas seu uso é perigoso, por tratar-se de planta extremamente tóxica.

Zornia diphylla (L.) Pers. - carrapicho.

A planta florida, sob forma de infuso ou decocto, é usada na disenteria.

Leguminosae-Mim.

Inga sessilis Mart. - ingá, angá, ingá ferradura.

A polpa do fruto, ao natural, é laxativa.

Stryphnodendron adstringens Mart. - barbatimão.

As cascas do caule, raízes ou folhas, sob a forma de decocto, infuso, pó, tintura ou melito, são usadas como cicatrizante, adstringente, para úlceras estomacais, feridas, limpar o útero, diarréia, nascer cabelo, na blenorragia, uretrite, hemorróida e como hemostático.

\section{Lilliaceae}

Allium ascalonicum L. - alho paulista.

O decocto dos bulbilhos é usado nas gripes, hipertensão, dores de ouvido e como tônico cardíaco.

Allium cepa L. - cebola de cabeça.

A maceração das folhas bulbares é usada na bronquite. 
Allium fistulosum L. - cebolinha.

$\mathrm{O}$ decocto de seus bulbos é usado como expectorante e na arteriosclerose.

Allium sativum $\mathrm{L}$. alho.

Os bulbinos amassados e cozidos na manteiga são usados nas gripes e como expectorante. Para sinusite é usado no vaporizador.

Aloe vera L. - babosa, áloe.

O sumo das folhas é usado como cicatrizante, nas doenças de pele e do couro cabeludo, nas parasitoses externas (piolho e carrapato) e ainda é utilizado nas hemorróidas e infestações por oxiúrus.

Asparagus officinalis L. - aspargo, milindre.

Toda a planta, sob forma de infuso, decocto, tintura ou extrato-fluido, é usada como diurético, sedativo, anti-hipertensivo, calmante, obesidade, na hidropsia e problemas do coração.

\section{Loganiaceae}

Strychnos pseudoquina St. Hil. - quina mineira.

A casca do caule, sob a forma de pó, é cicatrizante e na cachaça é usada para o fígado.

\section{Loronthaceae}

Phoradendron crassifolium (Pohl.) Eichl. - erva de passarinho, erva pombeiro. As folhas, sob a forma de decocto, são usadas para lepra, sarna e furúnculo.

Struthanthus marginathus Blume - erva de passarinho.

$\mathrm{O}$ decocto ou sumo é usado nas pneumonias.

\section{Lycopodiaceae}

Lycopodiella cernua (L.) Pichi-Sermolli - licopódio.

$\mathrm{O}$ decocto da planta inteira é diurético. Os esporos são vulnerários.

Lycopodium clavatum L. - licopódio.

Os esporos são secativos e diuréticos.

\section{Lythraceae}

Cuphea balsamona L. - sete-sangrias.

Toda a planta, sob a forma de infuso e decocto, é usada na arteriosclerose, hipertensão arterial e palpitações cardíacas.

\section{Malvaceae}

Abelmoschus esculentus (L.) Moech. - quiabo.

Os frutos ou sementes, cozidos, são emolientes. A semente, sob decocção, é preventiva na picada de cobra.

Gossypium herbaceum L. - algodão.

O sumo das folhas é usado nas inflamações uterinas.

Malva sylvestris L. - malva.

As folhas ou flores, em decocção, são usadas em inflamações da boca e garganta, como calmante e peitoral. 
Plantas medicinais de Minas Gerais...

Malpighiaceae

Banisteriopsis argyrophylla Juss. - cipó prata, murici.

As raízes em decocção, são usadas em inflamações, hemorragias ovarianas e na gonorréia. As folhas e caules, em decocção, são usadas nas doenças renais.

\section{Meliaceae}

Melia azedarach L. - cinamomo, Santa Bárbara.

As folhas, em forma de infuso ou decocto, são usadas como adstringente, estomacal, anti-histérico, anti-diarréico e emenagogo.

\section{Monimiaceae}

Siparuna guyanensis Aubl. - negramina.

As folhas ou raízes, sob a forma de chá quente com açucar ou sal, são usadas nas inflamações. Toda a planta, sob forma de chá frio, é usada na cefalalgia, reumatismo e gripes.

\section{Moraceae}

Brosimum gaudichaudii Trec. - mamacadela, inharaé, cabo verde, apaé, mamajóia.

A folha, caule ou raiz, na forma de infuso, decocto ou vinho, são usadas contra gripe, bronquite, manchas da pele, vitiligo, como depurativo, e para a circulação do coração e cérebro.

Cecropia hololeuca Miq. - embaúba, embaúba branca, árvore da preguiça.

Os ramos novos ou folhas, em pó, são usados na hipertensão, enquanto as folhas, após decocção, são usadas contra bronquite.

Dorstenia multiformis Miq. - carapiá, contra erva, caiapiá.

O rizoma, sob a forma de decocto, é usado nas bronquites, dispnéias e como emanagogo e antiespasmódico nas cólicas uterinas. É antídoto contra picadas de cobra.

Ficus carica L. - figueira.

As folhas, em decocto, são usadas como emoliente e nas amigdalites. O látex retira verrugas. Na pele pode provocar queimaduras graves.

Morus alba L. - amoreira branca.

A folha, cozida em água, ou os frutos com açucar e mel, são usadas nos problemas de rins, fígado, infecção no baço, infecção na garganta e prisão de ventre.

Morus nigra L. - amoreira negra.

As folhas, em decocção, são vulnerários. Os frutos, ao natural ou em xarope, são usados como laxativo, peitoral, vermífugo e nas dores de garganta e de dente. A casca é usada em decocto, para bronquite e diabete.

Eucalyptus sp. - eucalipto, calipe, eucalipto canela.

As folhas, na forma de decocto, são usadas em alergias, problemas de garganta 
e tosse, estomacal, febrífugo e antisséptico.

Eucalyptus citriodora L. - eucalipto limão.

As folhas, sob a forma de infuso, são usadas em inalações na sinusite.

Eucaliptus globulus L. - eucalipto.

As folhas, sob a forma de infuso ou decocto, são usadas como estomacais anti-sépticas, febrífugas, balsâmicas.

Eugenia uniflora L. - pitangueira.

As folhas, sob a forma de infuso ou decocto, são usadas como diuréticas, antireumáticas, antidiarréicas, febrífugas e sialagogas.

Jambosa vulgaris L. - jambo amarelo.

As folhas, em decocto, são usadas na diabete.

Metaleuca leucadendron L. - sete cascas, cajepute, sete casacas.

As folhas e casca do caule, sob a forma de decocto, são usados como anti-séptico, balsâmico, estomacal, febrífugo.

Psidium sp. - goiabeira.

As folhas, em decocto, são usadas nas inflamações dentárias.

Psidium guajava L. - goiabeira branca.

O caule, sob a forma de infuso ou decocto, é usado como estomacal, adstringente, antidiarréico e afecções bucais.

Nyctaginaceae

Boerhavia hirsuta Willd. - erva tostão, pega pinto.

As raízes, em infuso ou decocto, são usadas na icterícia, hepatite, e nas febres como antimalárico.

Mirabilis jalapa L. - jalapa.

As raízes, em infuso, decocto, ou xarope, são usadas como laxantes.

Oleaceae

Jasminum sambac (L.) Aitom - jasmim.

Toda a planta é usada, em decocto, para doenças cardíacas.

Oxalidaceae

Averrhoa carambola L. - carambola.

As folhas, frutos e ramos novos, sob a forma de decocto, são usados como febrífugo, anti-hemorroidal, diurético, nos eczemas, infecções dos rins e bexiga e na diabete.

Oxalis spl. - azedinha, trevo.

As folhas e raízes, sob a forma de decocto e cataplasma, são usadas como diuréticas, refrescantes. febrífuga, cistites, colites e abcessos.

Oxalis sp2. - azedinha.

As folhas mastigadas, ou em decocto, são usadas como vulnerárias das feridas bucais.

Oxalis corniculata $\mathrm{L}$. - azedinha.

Toda a planta, em decocto, é usada como vermífugo infantil. 
Papavaraceae

Argemone mexicana L. - cardo santo, espinha de peixe.

A folha, sob a forma de infuso ou decocto, é usada como febrífuga, na enxaqueca, cefalalgia, pneumonias, como emética e diaforética.

Fumaria officinalis L. - fumária.

Toda a planta em decocto é usada como depurativa, tônica, amarga, diaforéticas, emenagoga, antiescorbútica, anti-sifilítica, e nas escrofuloses.

Papaver rhoeas L. - papoula rubra.

As pétalas, em decocto ou xarope, são usadas como béquicas.

Passifloraceae

Passiflora alata Dryand. - maracujá.

Sob a forma de infuso, decocto ou suco, as folhas e frutos são usados como calmante, diurético, emenagogo, na estafa, asma, hipertensão arterial, hemorróidas e suas inflamações. $O$ decocto ou doce das raízes são usados na hipertensão arterial, como calmante, cicatrizante. $O$ decocto da casca de suas raízes é usada como antidepressivo, sendo tóxica em altas doses. $\mathrm{O}$ sumo do arilo das sementes e folhas são usados como calmante, hipnótico, na estafa e asma. Passiflora edulis Sims. - maracujá de suco.

As folhas, em decocto, são usadas externamente em banhos nas varizes e feridas.

Phytolacaceae

Petiveria alliacea L. - erva guiné, erva pipi, guiné.

Toda a planta, sob a forma de decocto, infuso ou na cachaça, é usada, principalmente externamente, no reumatismo, dor de dentes, cefalalgias e como diurético e emenagogo. Em grandes doses é abortivo.

\section{Piperaceae}

Piper aduncum L. - jaborandi, João Borandi, tapa buraco, quebra tijela.

O caule e folhas, na forma de decocto ou pó, são usadas na queda de cabelo, dores em geral, como anestésico e como adstringente no pós-parto.

Piper regnelli C.DC. - capeba do Brasil.

As folhas, em infuso, decocto ou afogadas, são usadas como estimulantes, estomacais, afecções renais, hipertensão e nas cólicas do fígado.

Pathomorphe umbellata Miq. - capeba, pariparoba.

As folhas ou raízes, sob a forma de decocto ou infuso, são usadas para males do fígado e rins, úlceras, resfriados, bronquites, como diurético, febrífugo, depurativo, emenagogo, na icterícia, sífilis, leucorréia, nas afecções urinárias, furunculoses e queimaduras. A casca, em decocção, é usada nos problemas de vesícula.

\section{Plantaginaceae}

Plantago major L. - trançagem, tanchagem.

Toda a planta, em forma de decocto ou emplasto, é usada como vulnerária, an- 
tinflamatória principalmente em dores de garganta e inflamações uterinas, e nas doenças de pele.

Plantago tomentosa - tanchagem falsa.

As folhas, sob a forma de decocto, são usadas como antinflamatórias.

\section{Polygalaceae}

Bredmeyera laurifolia $\mathrm{Kl}$. - cervejinha do campo, guaranazinho.

As raízes, sob a forma de decocto, são usadas nas doenças do fígado e rins, principalmente como litagogo.

Polygala lancifolia St. Hil. - poligala, iodex.

A raiz, sob a forma de infuso e decocto, é usada como diurética, nas bronquites, expectorante, nos problemas renais e contusões.

Polygala paniculata L. - barba de S. Pedro.

A raiz, sob a forma de infuso ou decocto, é usada em afecções das vias respiratórias, expectorante, diurético e nas afecções da pele, uretra, útero, bexiga e rins.

Polygala urbani Chad. - polígala.

Tem a mesma indicação das polígalas anteriores.

\section{Polygonaceae}

Muehlembeckia platiclada Meissm, - fita de moça, solitária.

Os cladódios são usados como vermífugos.

Polygonum acre H.B.K. - erva de bicho.

Toda a planta. sob a forma de infuso, decocto, é usada em hemorróidas e eczemas.

Rumex obtusifolius L. - labaça.

A raiz sob a forma de infuso e decocto é usada como tônica, depurativa, purgativa, febrífuga, antiescorbútica e emética.

\section{Polypodiaceae}

Doryopteris ornithopus (Mett) J. Sm. - samambaia, sambambaia.

As folhas ou raízes são usadas, na cachaça ou como decocto, para o reumatismo.

Adiantum cuneatum Langs et Fisch. - avenca.

As folhas, sob a forma de xarope, infuso e decocto, são usadas como digestivo, emenagogo, peitoral, na artrite e reumatismo.

\section{Portulacaceae}

Portulaca oleracea L. - beldroega.

Toda a planta , em salada, é usada nas afecções do fígado, rins, é antiescorbútica, cicatrizante e diurética. 
As cascas do caule ou do fruto, em decocção, são usados nas inflamações de garganta, rouquidão, nas hemorragias de ovário e útero, como vermífugo e para fortalecer o couro cabeludo.

\section{Rosaceae}

Cydonia ablonga Miller. - marmeleiro.

Os frutos em decocção ou geléia, são usados como antidiarréicos.

Eriobotrya japonica (Thumb.) Lindley - nespereira, ameixa amarela.

As folhas novas, em decocção, são usadas como diurético, no reumatismo, arteriosclerose, como antidiarréico e nas hemorróidas. Os frutos são laxativos, emolientes, e usados ainda nas tosses e resfriados.

Fragaria vesca L. - morangueiro, fragaia.

As folhas e raízes, sob a forma de decocto ou infuso, são usadas nas inflamações bucais, na hepatite, icterícia, diarréia, como diurético, depurativo e emenagogo. $\mathrm{O}$ fruto ao natural é utilizado em aftas, como edulcorante e adstringente.

Malus domestica Borkh - macieira, mação.

As cascas do fruto, em decocção, são digestivas após as refeições.

Rubus erythrocladus Mart. - amoreira do Brasil.

As sumidades floridas, em decocção ou garrafadas, são usadas nas dores de garganta ou como vermífugas. As folhas, caule e flores, sob a forma de decocto ou xarope são usadas nas dores de garganta e dentes, rins, bexiga, nas bronquites, diabete, como vermífugo e diurético.

Rubus rosaefolius Smith. - framboesa do Brasil.

$\mathrm{O}$ decocto ou infuso dos brotos é usado como depurativo, nas afecções renais e como refrescante.

Rosa sp. - rosa verde.

As pétalas são usadas como laxativo.

Rosa centifolia L. - rosa branca, rosa, roseira.

As pétalas, sob a forma de infuso ou decocto, são usadas como laxativos, nas doenças de pele e do útero.

\section{Rubiaceae}

Borreria sp. - cordão de frade branco, falsa poaia.

As folhas, sob a forma de decocto, é usada nas hemorróidas.

Cephaelis ipecacuanha (Brot.) Tussac. - poaia verdadeira, ipeca.

As raízes, em decocto ou xarope, são usadas nas tosses e bronquites.

Coffea arabica L. - café, cafeeiro.

As folhas, em infuso, são usadas como estimulante, diurético, na obesidade e diabete. As sementes, em infuso ou decocto, na cefaléia e como estimulante.

Genipa americana L. - genipapo.

Os frutos, ao natural, são tônicos, estomacais e diuréticos. A casca do caule, em infuso ou decocto, é utilizada para os mesmos fins.

Palicourea rigida H.B.K. - bate caixa, Dom Bernardo, douradinha do campo.

$\mathrm{O}$ decocto das folhas e raízes é usado nas doenças de pele como anti-sifilítico e 
vulnerário. As folhas e casca do caule, em decocção, são usadas como depurativas, usadas nas doenças renais e nas inflamações do ovário.

Remigea ferruginea (St. Hil.)DC. - quina da serra, quina do campo, quina brasileira, quina mineira, quina rosa.

A casca do caule, sob a forma de infuso, pó, decocto, é usada como tônica e amargo e antiinflamatória. No vinho, é usada contra a anemia.

Richardia brasiliensis Gomez - poaia do campo.

A raiz, sob a forma de infuso ou decocto, é usada como expectorante, emético e diaforético.

Richardia scabra L. - poaia do campo falsa.

Toda a planta, sob a forma de decocto, é usada como laxante.

Rudgea virbunoides Benth. - congonha de bugre, bugre, cotó-cotó.

$\mathrm{O}$ decocto das folhas é usado como diurético, nas doenças renais e nas úlceras estomacais. A raiz, em decocção, é usada no reumatismo, angina pectoris, gota, hipertensão, nas doenças renais e circulatórias.

Sabicea cana Hook. - sangue de Cristo, vinho do campo.

$\mathrm{O}$ decocto das folhas ou sumidades floridas é usado para prisão de ventre e a infusão ou decocto da raiz, para doenças venéreas.

\section{Rutaceae}

Citrus sp. - limoeiro.

Folhas e frutos, em decocção, suco ou melito, são usados nas gripes, rouquidão, nas bronquites, furunculoses e como aperitivo.

Citrus deliciosus L. - mixirica, tangerina.

$\mathrm{O}$ decocto das folhas é usado nas gripes e como febrífugo.

Citrus medica L - lima, lima de bico.

As folhas, sob a forma de decocto, são usadas nas cefaléias. A casca da árvore, em decocto, é usada na debilidade cardíaca e a fruta usada nas gengivites.

Citrus limon (L.) Burman F. - limão galego.

A folha ou casca do fruto, em decocção, são usadas nas gripes, sinusites e diabetes.

Citrus sinensis (L.) Osbeck - laranjeira.

As folhas ou flores, sob forma de decocto, são usadas no tétano, gripes, como expectorante, calmante e nas cefalalgias.

Esembeckia febrifuga A. Juss. - três folhas, laranjeira do mato, quina do mato.

A casca do caule, sob a forma de decocto, é usada como febrífugo.

Ruta graveolens $\mathrm{L}$. - arruda.

Toda a planta, sob a forma de infuso, decocto, maceração e colírio, é usada como emanagoga, nas doenças cardíacas, nas otites e infecções oculares. Internamente é extremamente tóxica, podendo causar a morte. É usada, externamente, para combater sarnas e piolhos. 
regularizadora das funções intestinais.

Sapindus saponaria L. - sabão de soldado, sabãozinho, sabão de gentio.

A raiz sob a forma de decocto é usada na sarna.

Scrophulariaceae

Cymbalaria muralis P. Gaertner, Meyer et Scherb - cimbalária.

A planta com as flores, sob a forma de infuso e decocto, é usada como tônico. Scoparia dulcis $\mathrm{L}$. - vassourinha doce.

Toda a planta, sob a forma de decocto e infuso, é usada como peitoral, emenagogo e febrífugo.

\section{Smilacaceae}

Smilax japecanga Griseb - japicanga, japecanga, salsaparrilha falsa, salsaparrilha.

As raízes, em decocção, são usadas na gonorréia, reumatismos, eczemas, afecções do aparelho genital feminino, e como depurativo.

Herreria salsaparrilha Mart. - salsaparrilha verdadeira.

As raízes, sob a forma de infuso, decocto e pó, são usadas como depurativas, anti-sifilíticas e sudoríferas.

\section{Solanaceae}

Brunfelsia uniflora (Pohl.) D. Donn. - manacá.

Raízes e folhas sob a forma de decocto e infuso, são usadas como purgativo, anti-reumático, diurético, emenagogo, abortivo e na sífilis.

Brungmansia suaveolens (Humb. \& Bomp. ex Wills.) Berot e J.S. Presl. trombeteira, saia branca, zabumba.

A folha, sob a forma de cigarro, é usada na asma. Sob a forma de emplasto é usada na consolidação da fratura óssea. Sob a forma de colírio, como midriático. Sob a forma de decocto, como antiespasmódico.

Capsicum frutecens Willd. - pimenta malagueta.

$\mathrm{O}$ sumo das folhas é usado na erisipela.

Cestrum noturnum L. - dama da noite.

A batata e a flor associadas, sob a forma de infuso e vinho, são usadas na gastrointerite. Em associação à salsaparrilha são usadas contra a inflamação. A flor, sob a forma de infuso, é usada como litagoga e no corrimento vaginal.

Datura stramonium L. - estramônio.

As folhas, sob a forma de cigarro, são usadas na asma e sob a forma de decocto como antiespasmódicas. Planta altamente tóxica.

Lycopersicon lycopersicum (L.) Karsten. - tomate, tomateiro.

As folhas maceradas, colocadas sobre as queimaduras da pele, atuam como cicatrizantes.

Nicotiana tabacum L. - fumo, tabaco.

As folhas, secas e pulverizadas, são usadas como antitetânico, esternutatórios. $\mathrm{O}$ decocto das folhas é usado nas parasitoses externas, como sarnas e piolhos.

Solanum sp. - jurubeba grande. 
Frutos e raízes, em decocção, infusão ou no vinho, são usados nas doenças do fígado e do baço, aperitivo, febrífugo, diabete.

Solanum americanum Miller. - erva moura.

Toda a planta, em infuso, decocto ou cataplasma, é usada em feridas, tumores, furunculoses, queimaduras, como sedativo, calmante e narcótico.

Solanum cernuum Vell. - braço de preguiça, braço de mono, panaceia.

Raízes e folhas, sob forma de infuso e xarope, são usadas na caxumba, como litagogo, vermífugo, depurativo, anti-sifilítico, diurético e nas doenças da pele.

Solanum jequiri Mart. - jequiri, jiquiri.

As folhas, em decocto, são usadas nas amigdalites ou como depurativo.

Solanum grandiflorum Ruiz et Pavon. - lobeira, fruta de lobo.

Flor, fruto ou raiz, sob forma de infuso e xarope, são usadas nas gripes, bronquites, cefalalgias, dores de garganta e coqueluches.

Solanum melogena $\mathrm{L}$. - beringela.

As folhas e fruto, em decocção, são usados como colagogo. $\mathrm{O}$ sumo do fruto é usado nas nefrites, cistites e como diuréticos. As folhas são usadas, como cataplasmas, nas queimaduras, abcessos, herpes, furúnculos. $\mathrm{O}$ sumo do fruto é usado para extirpar verrugas.

Solanum paniculatum L. - jurubeba, jurubeba do campo.

Frutos ou raízes são usados como estomacal e nas moléstias do fígado.

Solanum racemiflorum Dum. - Jiló.

O fruto cozido, em decocção, ou salada é utilizado nas úlceras do estômago, prisão de ventre, má digestão. Em infuso, no álcool ou cachaça para picada de insetos, e aliviar dores da picada de escorpião.

\section{Styracaceae}

Styrax camporum Pohl. - falso benjoim, botica inteira.

Casca do caule e folhas sob forma de infuso e decocto são usadas como depurativo nas febres.

\section{Sterculiaceae}

Sterculia chicha St. Hil. - chichá.

As sementes, sob a forma de decocto e infuso, são usadas como antidiarréico e tônico cardíaco.

\section{Theaceae}

Camellia sinensis (L.) Kuntze. - chá preto, chá da Índia.

As folhas, flores, sementes ou raízes, na forma de decocto, infuso, ou emplasto, são usadas como excitantes, estimulante, para os rins, expectorante, purgativo, diurético, diaforético, e doenças pulmonares.

\section{Tiliaceae}

Luhea divaricata Mart. - açoita cavalo, agoniada, açoita.

Casca do caule ou folhas, sob forma de infuso e xarope, são usadas na artrite, disenteria, hemorragia, reumatismo, leucorréia e tumores. 
Triumfetta semitriloba L. - carrapicho de calçada, carrapicho branco.

Toda a planta, sob forma de infuso ou decocto, é usada como diurética, antiblenorrágica, emoliente e adstringente.

\section{Tropeolaceae}

Tropeolum majus L. - chagas, cocleária, capuchinho, chagra, curiara.

As folhas, em infuso e decocto, são usadas como diurético e na furunculose. $O$ decocto, das folhas e sementes, é usado no tatamento do escorbuto e eczemas.

\section{Umbelliferae}

Apium graveolens L. - aipo.

As sementes, folhas ou raízes, sob forma de infuso e decocto, são diuréticas, carminativas e excitantes. A folha, em decocto e infuso, é usada para problemas cardíacos. O decocto do caule é usado em mulheres com infecção pós-parto.

Conium maculatum L. - cicuta.

As folhas, em infuso ou decocto, são usadas como antiespasmódicas, sedativas, nas escrofuloses, reumatismos e convulsões.

Coriandrum sativum L. - coentro.

Os frutos, ou toda a planta em decocção, são usados como carminativo, estomacais, aromáticos e na má digestão.

Foeniculum vulgare Miller. - funcho.

A folha, sob a forma de decocto, é laxante e estomacal. Os frutos, em decocto ou infuso, são usados como carminativo, estimulante, litagogo, galactogênico, antiespasmódicos.

Petroselium crispum (Miller) Nyman e A.W. Hill. - salsa.

As raízes ou toda a planta, sob a forma de decocto ou vinho, são usadas para inflamações uterinas, como tônico uterino, regulador das menstruações, carminativo e aromático.

Pimpinella anisum L. - aniz, erva doce.

O decocto das sementes é usado como carminativo, estomacal, e litagogo.

\section{Urticacee}

Parietaria officinalis L. - parietária, fura parede, paletária.

As folhas, sob forma de infuso e decocto, é usada nas cistites, moléstias inflamatórias e como cicatrizante.

Urtica sp. - urtiga, cansação.

As folhas em decocção são usadas nas moléstias cutâneas, e como adstringente, e hemostático.

\section{Usneaceae}

Usnea barbata Fries. - barba de pau.

O talo, em pó ou sob a forma de decocto, é usado como secativo nas feridas úmidas e cicatrizante na lepra. 
Aloysia triphylla (L'Her) Britton. - cidrila, erva cidreira, erva cidreira de árvore, erva cidreira de rama.

As folhas ou flores, sob forma de infuso e decocto, são usadas nas gripes, resfriados, palpitações do coração, e como expectorante, emoliente, febrífugo, calmante, diurético. As flores são aromáticas.

Lantana camara L. - camara, cambará.

As folhas, sob forma de infuso, decocto ou xarope, são usadas nas gripes, febres, bronquites, rouquidão e outras infecções das vias respiratórias. Em altas doses é tóxica.

Lippia sp. - alfazema falsa.

As flores são usadas na cefaléia.

Stachytarpheta cayennsis (Rich.) Vahl. - gervão, gervão roxo, gerbão.

Raízes ou folhas, em infuso, decocto, xarope, são usadas como febrífugas, béquicas, vulnerárias, tônicas, estomacais, na hepatite e vermífugas.

Vitex agnus-castus L. - pimenta da costa.

Sob a forma de infuso, as sementes são usadas para cólicas, como carminativa e antiemética.

Vitex polygama Cham. - azeitona do mato, Maria preta.

As folhas, sob a forma de infuso ou decocto, são usadas como poderoso antireumático, diurético e nos problemas renais.

Vitex sellowiana Cham. - azeitona do mato, Maria preta.

As folhas, sob a forma de decocto ou infuso, são usadas como poderoso antireumático e depurativas.

\section{Violaceae}

Anchietea salutaris St. Hil. - suma branca.

A raiz, em decocção, é usada nas úlceras, eczemas, fogo selvagem e nos problemas renais, ovarianos e intestinais.

Viola adorata L. - violeta de cheiro.

A folha, em decocção, misturada à manteiga de cacau, é expectorante.

Vitaceae

Vitis vinifera L. - parreira, videira.

O suco do fruto é usado como laxante, colagogo, e litagogo. As folhas, em decocto ou salada, são usadas na urticária e na arteriosclerose.

\section{Vochysiaceae}

Qualea sp. - pau terra.

$\mathrm{O}$ decocto das folhas é usado para úlcera, gastrite, ameba, diarréia com sangue e cólicas intestinais.

\section{Winteraceae}

Drymis winteri Forster et Forster. - casca d'anta.

A casca do caule, em maceração, na água ou cachaça, ou em decocção é usada nos problemas estomacais, nas diarréias, anemias, impotência sexual, como di- 
gestiva e antiemética.

Xyridaceae

Xyris laxifolia Mart. - junco, ruibarbo, ruibarbo do campo, ruibarbo amarelo, ruibarbo vermelho.

A raiz, batida e dissolvida em óleo de rícino, é usada na insolação. A batata da raiz, em decocção, é usada nas doenças venéreas, úlceras da pele e fístulas.

\section{Zingiberaceae}

Costus spiralis Rosc. - cana de macaco, caninha do brejo, caninha de macaco, cana fista, cana do reino.

Toda a planta é usada, em infuso ou decocto, como litagoga, diurética, e nas anemias. As folhas ou raízes são usadas, sob forma de infuso no vinho, para diarréia e gastroenterite.

Renealmia exaltata L. - pacová.

Sementes, raízes e casca do caule, sob infusão ou no vinho branco, são usadas como excitante, carminativo, estomacal, anti-helmíntico e no reumatismo.

Zingiber officinale Roscoe. - gengibre, cerveja do campo.

As raízes e folhas, sob a forma de infuso, decocto ou ao natural, são usadas na gripe, dor de dente, amigdalites, na afonia, reumatismo, emenagogo, peitoral e abortivas. 
Tabela II

Localização das entrevistas em Minas Gerais - Cidades visitadas

Abaeté-67
Almenara-01
Araxá-00
Araújos-66
Arcos-42
Azurita
Barbacena-02
Barão de Cocais-39
Belo Hte.-03
Betim-04
Boa Esperança-44
Bom Despacho-31
Brumadinho-52
Caeté-38
Capitólio-59
Caraça
Carmópolis-05
Conceição-06
Congonhas-51
Contagem-07
Corinto-08
Coronel Fab.-34
Divinópolis-09
Entre Rios-65
Ermida
Felixlândia-55
Formiga-43
Funilândia
Gov. Valadares-33
Ibirité
Inhaúma
Ipatinga-35
Itabira-10
Itabirito-49
Itacarambi-64
Itaguara-11
Itaúna-53
Joatuba
João Monlevade-12
Ladainha
Lagoa da Prata-40
Lagoa Sto. Antônio

Lagoa Dourada-13

Lagoa Formosa-47

Lagoa Santa-56

Lavras-14

Manhuaçu-15

Maravilhas

Mateus Leme-61

Matozinhos-16

Moeda-62

Monte Carmelo-45

Montes Claros-32

Morada Nova-17

Mota

Nanuque-48

Nova Era-36

Oliveira-18

Ouro Preto-50

Pará de Minas-19

Patos de Minas-46

Patrocínio-60

Pedro Leopoldo-21

Pitangui-20

Pium-1

Pompéu-54

Riberão Neves-22

Rio Piracocaba-23

Sabará-37

Santa Luzia-24

Serra Azul

Serra de Aimorés-52

Sete Lagoas-26

Senhora do Carmo

Santo Antônio-58

Sto. Antônio Monte

Sto. Cândido

São Gonçalo Pará-30

São Lourenço-25

Teófilo Otoni-27

Tiros

Três Barras-63

Três Coraçōes-29

Uberaba-28

As localidades que não foram numeradas, não estão localizadas no mapa, por sua proximidade com outra cidade. 
Plantas medicinais de Minas Gerais...

Tabela III

Número de vezes que a espécie medicinal foi citada dentro de 1 faixa

Especificação

A

B

C

D

E

$\mathrm{F}$

G

$\mathrm{H}$

I

$\mathrm{J}$

K
Intervalo

$$
0-10
$$

$10-20$

$20-30$

$30-40$

$40-50$

$50-60$

$60-70$

$70-80$

$80-90$

$90-100$

$100-110$
Subtotal

240

56

27

14

16

8

7

4

5

0

2
Porcentagem \%

63,3

14,8

7,1

3,7

4,2

2,1

1,9

1,1

1,3

0,0

0,5

Grupo K: funcho e carqueija amarga

Grupo I: arruda, tanchagem, macaé, e quebra pedra falso.

Grupo H: erva cidreira (capim limão), panacéia (braço de preguiça), salsa, picão.

Grupo G: chuchum lágrima de N. Sra., boldo, alfavaca, alecrim (Labiatae), erva de Santa Maria. confrei.

Grupo F: hortelã branca, poejo, erva cidreira (Labiatae), goiabeira branca, romã, mamoeiro, erva de S. Joảo, losna.

Grupo E: assa-peixe, melão de S. Caetano, hortelã preta, levante, abacateiro, sucupira, pitangueira, erva guiné, capeba, rosa branca, congonha de bugre, laranjeira amarga, jurubeba, sabugueiro, macelina galega.

Grupo D: artemigem, alumâ, alfavaca de jardim, sálvia, jatobá, barbatimão, algodoeiro, mamacadela, eucalipto, erva de bicho, fumo, cidrila, gervão roxo, carobinha.

Grupo C: arnica verdadeira, dente de leão, folha de fortuna, mastruço, cavalinha, pé de perdiz, capim de S. José, mangericão branco, canela do Ceilăo, loureiro, unha de vaca, carrapicho de beiço de boi, maracujá, morangueiro, aipo, camará, cana de macaco, gengibre, piriquito, cajueiro, jarrinha, catuaba, cipó cravo, espinheira santa, mentrasto, alecrim do campo, caninha de macaco.

Grupo B: Emília, girassol, barbana, guaco, cipó cabeludo, serralha, bálsamo, mostarda negra, mentruz, bucha paulista, cipreste, mamona, sálvia peluda, mangerona, erva terrestre, cordão de frade, sassafraz, aspargo, embaúba branca, figueira, maracujá de suco, tanchagem falsa, eucalipto limão, barba de S. Pedro, cervejinha do campo, vassourinha doce, japicanga, salsaparilha, jiló, jurubebinha do campo, chagas, coentro, parietária, azeitona do mato.

Grupo A: Todas as demais, que são 240 espécies. 


\section{Tabela IV}

Distribuição em porcentagem de classe de idade de populares que usam plantas como medicamento, entrevistados em Minas Gerais no período de 1982-1984.

\section{Especificação}

A

B

C

D

E

F

G

H

I

$80-90$

$60-70$

$70-80$

63

28,0

Intervalo de idade

01

0,45

17

7,5

18

8,0

29

12,9

53

23,6

J

$90-100$

K

$100-110$
35

02

0,9

06

15,5

6

0,45

01 
Plantas medicinais de Minas Gerais...

\section{Tabela V}

Tipos de profissão mais frequentes entre os entrevistados. Período 1982-1984.

Profissão

Raizeiros

Donas de Casa

Domésticas

Costureiras

Agregados da Fazenda

Lavradores

Umbandistas

Professoras

Lavadeiras

Curandeiros

Vendedores

Farmacêuticos

Pedreiro

Carpinteiro

Funcionário Público

Porteiro

Pescador

Estudante

Outras*

Número de citações Porcentagem

55

53

50

12

9

7

5

5

4

4

4

4

3

2

2

2

2

2

$1 \times(16)$
22,8

21,9

20,7

4,9

3,7

2,9

2,1

2,1

1,6

1,6

1,6

1,6

1,2

0,8

0,8

0,8

0.8

0,8

0,4

* Foram citadas uma vez apenas, viajante, operário, secretário, contador, doceira, eletricista, marceneiro, acumputurista, representante comercial, mecânico, advogado, garimpeiro, jardineiro.

Observação: Foram entrevistados 130 homens e 177 mulheres. Quanto ao grau de instrução, verificamos que a maior parte é alfabetizada, poucos têm o primário, secundário ou instrução superior. Quase todos aprenderam a conhecer plantas com os pais ou avós, poucus com amigos ou em livros, 3 deles receberam instrução de espíritos. 


\section{Discussão}

Pelos dados acima obtidos podemos concluir que o uso de plantas medicinais é largamente difundido em Minas Gerais, conhecendo-se até o presente momento plantas de 84 famílias diferentes e que são usadas para os mais diversos fins curativos.

Como muitas vezes o vegetal coletado estava incompleto, muitas espécies que são usadas como medicinal não foram computadas no trabalho, por não ter sido possível, determiná-las botanicamente.

Como foram encontradas muitas espécies botânicas com o mesmo nome científico, é perigoso propagar o uso de plantas medicinais, usando-se somente o nome vulgar. Muitas espécies têm também muitos nomes vulgares, variando de região para região em Minas Gerais. O macaé, por exemplo, é conhecido em Minas por 13 nomes vulgares diferentes.

As pessoas, que fazem uso de plantas medicinais são quase sempre de baixa renda e pouca instrução. Aprenderam sobre elas com seus pais e avós, estando sobretudo na faixa etária compreendida entre 50 e 70 anos. Com 19 anos, encontramos apenas 1 indivíduo.

Existem muitos raizeiros vivendo da comercialização das plantas medicinais, em todas as regiões de Minas Gerais.

As famílias botânicas, onde encontramos o maior número de espécies medicinais, em Minas Gerais até o presente momento são: Compositae, Leguminosae, Labiatae e Solanaceae.

Os gêneros, onde encontramos maior número de espécies medicinais em Minas Gerais até o presente momento, são: Solanum, Ocimum, Allium, Mikania, Citrus e Maytenus.

Esse trabalho deve servir como base para os estudiosos de química, farmacologia e parasitologia, como um trabalho de ensaio e erro feito pela população durante muitos anos de experiência com as plantas, e que, espera um retorno, em bases científicas para consagrá-lo.

\section{Glossário}

Formas farmacêuticas mais comuns

Alcolatura - Fragmentos frescos da planta extraídos com álcool.

Infuso-obtido, vertendo-se água fervendo sobre fragmentos da planta.

Decocto - Chá, obtido pelo cozimento da planta.

Emplastro - Em uso popular, é o uso da planta fresca sobre o local doente.

Maceração - Forma farmacêutica, obtida por extração com água fria.

Vinho - Forma farmacêutica cujo veículo é o vinho.

Termos farmacêuticos menos conhecidos usados no trabalho.

Abcesso - Acúmulo de pús em uma cavidade.

Adstringente - Contrai os tecidos.

Afonia - Perda da voz, rouquidão.

Afrodisíaco - Provoca excitação sexual. 
Albuminúrico - Presença de albumina na urina.

Anti-helmíntico - Contra vermes helmintos.

Anúria - Diminuição ou supressão da secreção urinária.

Béquico - Contra tosse.

Blenorragia - Doença sexualmente transmissível.

Carminativo - Impede ou expulsa os gases intestinais.

Cefaléia ou cefalalgia - Dor de cabeça.

Cistite - Inflamação da bexiga.

Colagogo - Desperta a secreção biliar.

Depurativo - Libera o organismo de substâncias nocivas.

Diaforético - Produz sudação.

Disenteria - Evacuação acompanhada de cólicas, catarros e sangue.

Dispnéia - Respiração difícil.

Eczemas - Afecção da pele com vesículas serosas e transparentes.

Edulcorante - Adoçante, ou que mascara o sabor desagradável de outros compostos.

Emenagogo - Que estimula a menstruação.

Emético - Vomitivo.

Emoliente - Amolece os tecidos inflamados, favorecendo a circulação.

Escrofuloses - Inflamação dos gânglios.

Espasmódicos - Rigidez muscular.

Galactagogo - Estimula a secreção láctea.

Hemostático - Que estanca hemorragia.

Hidropsia - Acúmulo anormal de líquidos nos tecidos.

Histeria - Crise de nervos, antigamente, relativa apenas às mulheres.

Icterícia - Presença de bile no sangue, tornando a pele amarela.

Leucorréia - corrimento branco.

Litagogo - Expulsa cálculo.

Litíase - Formação de pedras nas vias urinárias.

Prurido - Coceira.

Sialagogo - Provoca secreção salivar.

Sinapismo - Cataplasma de Mostarda na linguagem oficial, mas o povo usa esse termo de modo diferente, significando o uso ao natural sobre o ferimento ou orgão doente.

Sinusite - Inflamação da mucosa dos sinus.

Vermífugo - Que expulsa os vermes.

Vulnerário - Que cura feridas.

\section{Agradecimentos}

Aos raizeiros e populares que nos transmitiram seus conhecimentos e plantas.

Aos colegas do Departamento de Botânica, pelo incentivo diário.

Aos alunos do IV período de Farmácia que cursaram a disciplina Botânica 
Aplicada à Farmácia de 1982 a 1986, e alunos de Plantas Medicinais do Curso de Ciências Biológicas, de igual período, pelas entrevistas e coletas junto aos raizeiros de Minas Gerais, sem os quais essa pesquisa não seria realizada.

Aos monitores Carla Trópia Requena, Railson Warnel Kfuri e às alunas Jacqueline Aparecida Takahashi e Raquel Gouveia dos Santos, pela ajuda prestada, quando da elaboração desse trabalho.

Â Helen Mesquita Grandi, pela revisão de Português e ao Anthony Brome Rylands, pela revisão do Inglês.

Ao $\mathrm{CPq} / \mathrm{UFMG}$, pela ajuda financeira. 


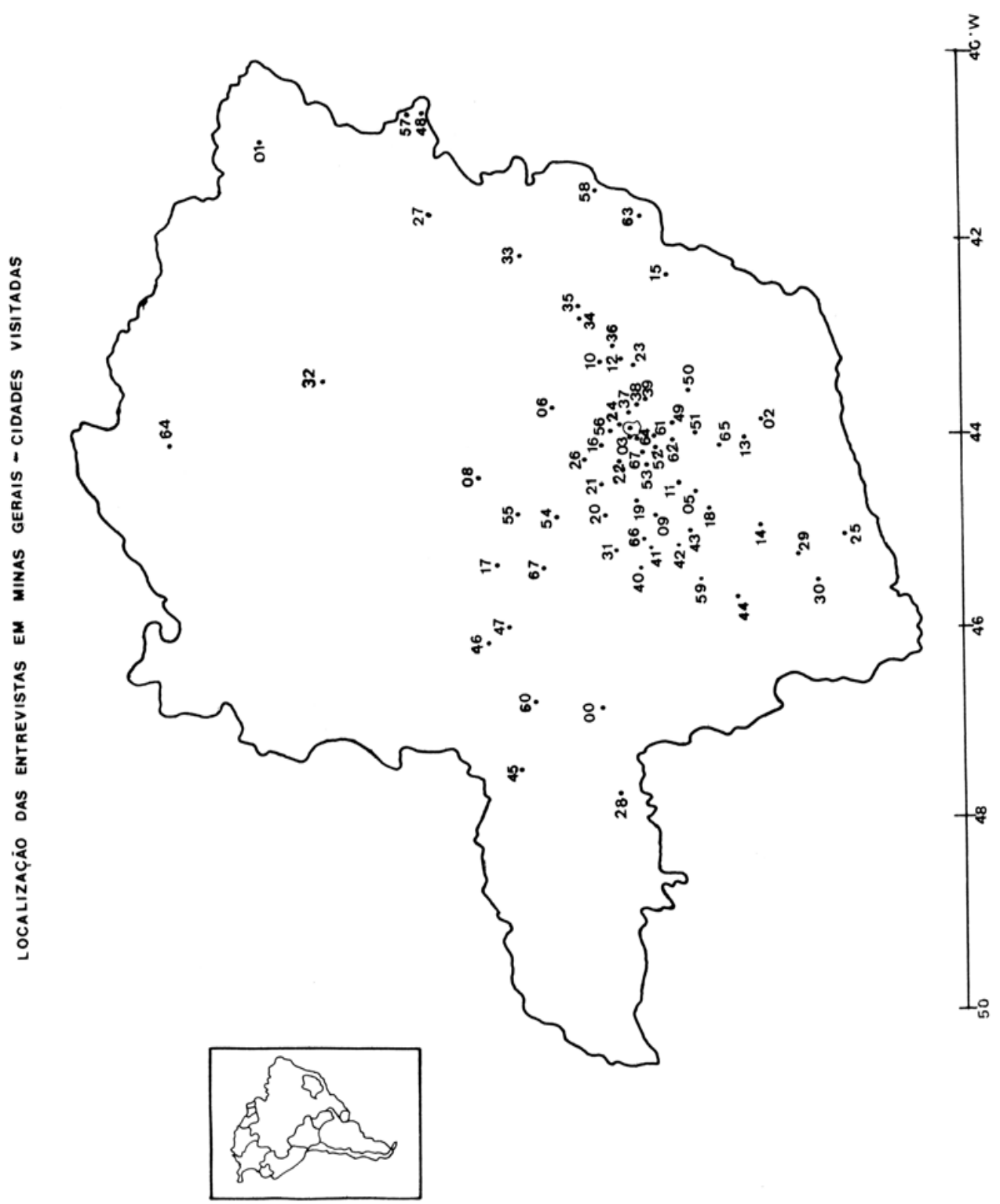


GRÁFICO-1

Grafico de setor rulativo ao numero de vezes que a espécie medicinal fo $i$

citada dentro de uma faixa.

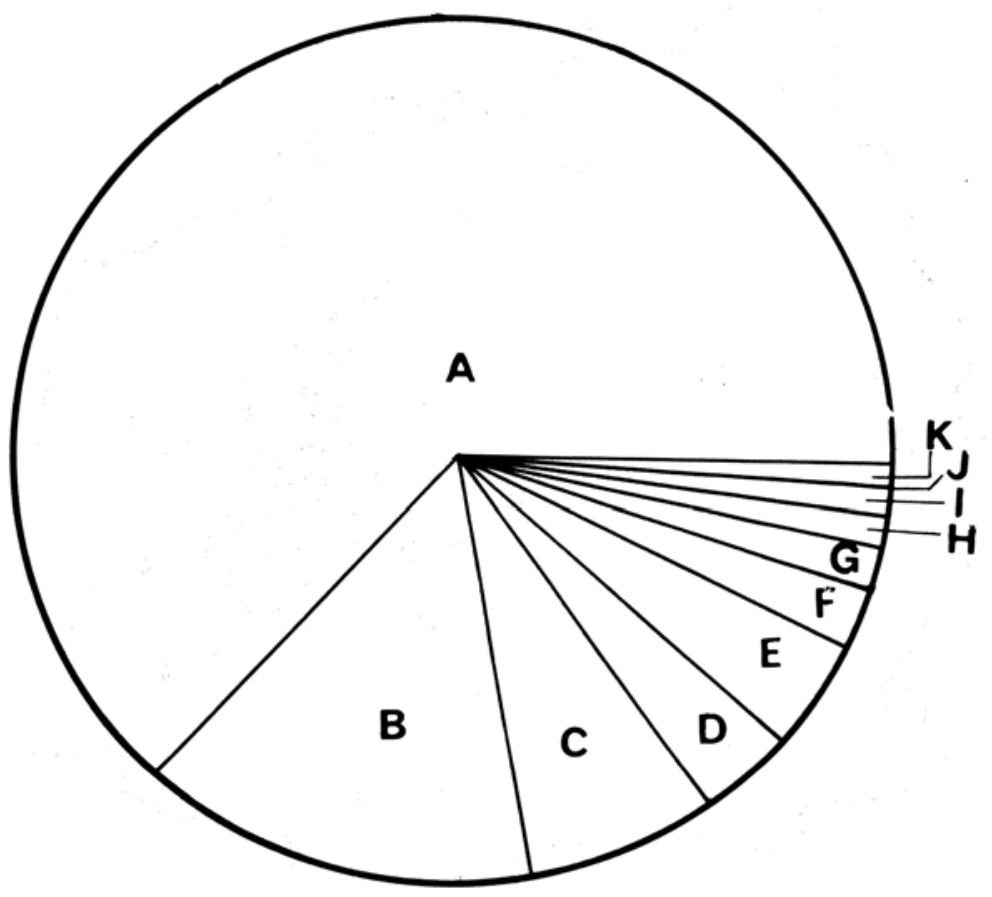

\section{LEGENDA}

$\begin{array}{lc}\text { A- 0-10: } & 63,3 \% \\ \text { B- } 10-20: & 14,8 \% \\ \text { C- 20-30: } & 7,1 \% \\ \text { D- 30-40: } & 3,7 \% \\ \mathbf{E}-40-150: & 4,2 \% \\ \mathbf{F}-50-60: & 2,1 \% \\ \mathbf{G}-60-70: & \mathbf{1 , 9} \% \\ \mathbf{H}-70-80: & 1,1 \% \\ \mathbf{I}-\mathbf{8 0 - 1 9 0 :} & \mathbf{1 , 3} \% \\ \mathbf{J}-90-100: & 0,0 \% \\ \mathbf{K}-100-110: & 0,5 \%\end{array}$


GRÁFICO - 2

Número de vezes que a espécie medicinal foi citada dentro de uma faixa.

$\%$ DE

VEZES

100

75

75

of

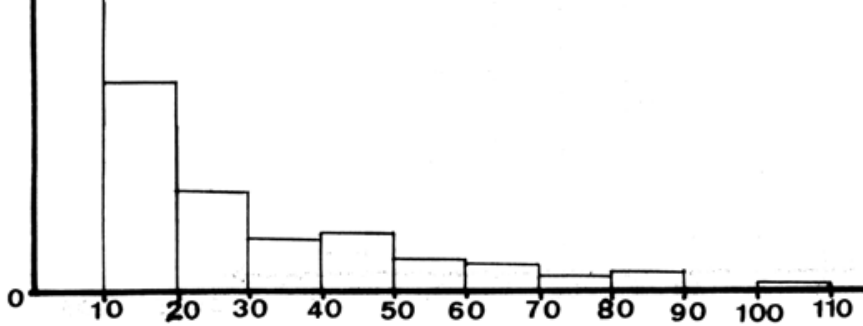


GRÁFICO - 3

Histograma relativos a porcentagem $\bullet$ a idade dos entrevistados no perido de 1984-86.

$\%$ Dos

EN TREVISTADOS

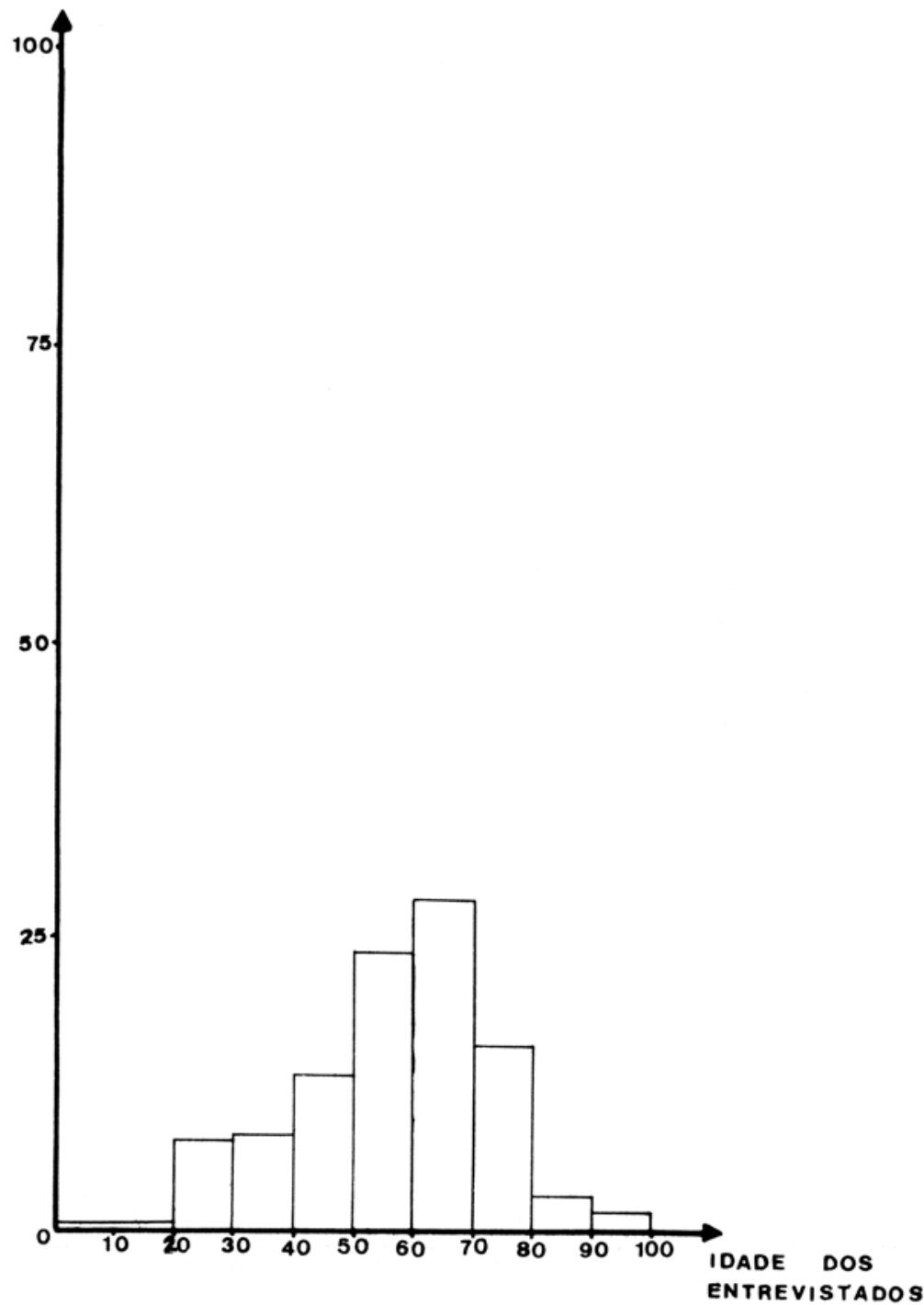

